\title{
Use of item response theory and latent class analysis to link poly-substance use disorders with addiction severity, HIV risk, and quality of life among opioid-dependent patients in the Clinical Trials Network ${ }^{*}$
}

\author{
Li-Tzy Wu ${ }^{1,{ }^{* *}}$, Walter Ling ${ }^{2}$, Bruce Burchett ${ }^{1}$, Dan G. Blazer ${ }^{1}$, Chongming Yang ${ }^{3}$, Jeng-Jong \\ Pan $^{4}$, Bryce B. Reeve ${ }^{5}$, and George E. Woody 6 \\ ${ }^{1}$ Department of Psychiatry and Behavioral Sciences, School of Medicine, Duke University \\ Medical Center, Durham, NC 27710, USA \\ 2 David Geffen School of Medicine, NPI/Integrated Substance Abuse Programs, University of \\ California, Los Angeles, CA 90025, USA \\ 3 Social Science Research Institute, Duke University, Durham, NC 27705, USA \\ 4 Veterans Health Administration, Washington, DC 20420, USA \\ ${ }^{5}$ Gillings School of Global Public Health, University of North Carolina at Chapel Hill, NC 27599, \\ USA \\ ${ }^{6}$ Department of Psychiatry, School of Medicine, University of Pennsylvania and Treatment \\ Research Institute, Philadelphia, PA 19104, USA
}

\begin{abstract}
Background-This study applied item response theory (IRT) and latent class analysis (LCA) procedures to examine the dimensionality and heterogeneity of comorbid substance use disorders (SUDs) and explored their utility for standard clinical assessments, including the Addiction Severity Index (ASI), HIV Risk Behavior Scale (HRBS), and SF-36 quality-of-life measures.

Methods-The sample included 343 opioid-dependent patients enrolled in two national multisite studies of the U.S. National Drug Abuse Treatment Clinical Trials Network (CTN001-002). Patients were recruited from inpatient and outpatient addiction treatment settings at 12 programs. Data were analyzed by factor analysis, IRT, LCA, and latent regression procedures.
\end{abstract}

\footnotetext{
*A Supplementary figure for this article can be found by accessing the online version at http://dx.doi.org by entering doi:...... (C) 2011 Elsevier Ireland Ltd. All rights reserved.

${ }^{* *}$ Corresponding author: Li-Tzy Wu, Duke University School of Medicine, Department of Psychiatry and Behavioral Sciences, Duke University Medical Center, Box 3419, Durham, NC 27710, USA; tel.: 919-668-6067; litzy.wu@duke.edu.

Contributors: Dr. Wu designed the research questions and wrote the initial draft. Drs. Wu, Burchett, Yang, Pan, and Reeve contributed to the data analysis. All authors contributed to the interpretation of the data and revision of the paper. Dr. Ling was the principal investigator of the original two trials.

Conflicts of Interest: Dr. Ling has received research funding from Titan Pharmaceuticals, Reckitt Benckiser, and Hythiam; he has served as a member of the Advisory Board for the US World Meds. Dr. Woody is a member of the RADARS post-marketing study external advisory group whose job is to assess abuse of prescription medications. Denver Health administers RADARS, and pharmaceutical companies support its work. The other authors have no conflicts of interest to disclose.

Publisher's Disclaimer: This is a PDF file of an unedited manuscript that has been accepted for publication. As a service to our customers we are providing this early version of the manuscript. The manuscript will undergo copyediting, typesetting, and review of the resulting proof before it is published in its final citable form. Please note that during the production process errors may be discovered which could affect the content, and all legal disclaimers that apply to the journal pertain.
} 
Results-A two-class LCA model fit dichotomous SUD data empirically better than oneparameter and two-parameter IRT models. LCA distinguished $10 \%$ of severe comorbid opioiddependent individuals who had high rates of all SUDs examined-especially amphetamine and sedative abuse/dependence-from the remaining $90 \%$ who had SUDs other than amphetamine and sedative abuse/dependence (entropy=0.99). Item-level results from both one-parameter and twoparameter IRT models also found that amphetamine and sedative abuse/dependence tapped the more severe end of the latent poly-SUD trait. Regardless of whether SUDs were defined as a continuous trait or categorically, individuals characterized by a high level of poly-SUD demonstrated more psychiatric problems and HIV risk behaviors.

Conclusions-A combined application of categorical and dimensional latent approaches may improve the understanding of comorbid SUDs and their associations with other clinical indicators. Abuse of sedatives and methamphetamine may serve as a useful marker for identifying subsets of opioid-dependent individuals with needs for more intensive interventions.

\section{Keywords}

clinical trials network; comorbidity; item response theory; latent class analysis; multiple

indicators-multiple causes model; opioid dependence; polysubstance use; substance use disorders

\section{Introduction}

Opioid use disorders are among the most prevalent substance use disorders (SUDs) in addiction treatment programs, and comorbid SUDs are widespread among patients with opioid addiction (Strain, 2002; Substance Abuse and Mental Health Services Administration [SAMHSA], 2009). Due to a significant increase in prescription opioid abuse, opioid use disorders now comprise the second most prevalent drug use disorder in the United States (following marijuana), and opioids are associated with the highest rate of increase in addiction treatment use (SAMHSA, 2010). Evidence from the National Epidemiologic Survey on Alcohol and Related Conditions confirms a higher lifetime rate of SUDs (alcohol, nicotine, any drug) among heroin users (63-85\%), other opioid users (53-76\%), and heroinother opioid users (72-94\%) than among non-opioid drug users (34-63\%) (Wu et al., 2011).

Comorbid SUDs complicate clinical courses and treatment designs (Strain, 2002; Veilleux et al., 2010). Although researchers have highlighted the significance of incorporating full diagnostic configurations into treatment and research designs (Carroll and Rounsaville, 2002; Rounsaville et al., 2003), little is known about how to conceptualize and classify cooccurrences of multiple SUDs and how to link this information with other clinical indicators to inform research and the forthcoming fifth edition of the Diagnostic and Statistical Manual of Mental Disorders (DSM-5) (Saunders et al., 2007). Here, we apply item response theory (IRT) and latent class analyses (LCA) to examine co-occurring SUDs, employing regression procedures to link empirically defined latent variables with standard assessments of clinical severity indicators.

The IRT approach to SUDs recognizes variability in the risk and manifestations of the addiction severity continuum (Kirisci et al., 2006; Vanyukov et al., 2009). It assumes that a latent severity trait underlies response patterns of SUDs; severity refers to various degrees of maladaptive substance use behaviors and consequences measured by DSM-IV SUD criteria. This approach suggests that SUDs are a continuous condition and that the severity level increases as greater numbers of SUDs are present. In particular, IRT can evaluate how items perform (e.g., item difficulty) along the underlying latent liability. IRT studies of DSM-IV SUD criteria for individual SUD have found a unidimensional latent trait underlying 
diagnostic symptoms for each disorder (Gillespie et al., 2007; Langenbucher et al., 2004; Saha et al., 2006; Wu et al., 2010a; Wu et al., 2009a Wu et al., 2009b).

These IRT studies focus mainly on an individual substance class. Because polysubstance use is common among drug abusers, and the risk for addiction generally is accounted for by shared, multiple familial and environmental factors (Kendler et al., 2003; Leri et al., 2003; Rounsaville et al., 2003; Tsuang et al., 1998), it is likely that various SUDs indicate a unifying dimensional severity trait (Kirisci et al., 2006). Very few studies have examined polysubstance use as reflecting a single latent trait. Kirisci et al. (2002) examined lifetime use of 10 substance classes and found that the 10 binary substance use variables were scalable as an index for a continuous latent trait score, which was positively associated with the level of other drug use-related problems. Kirisci et al. (2006) further applied IRT analysis to examine dichotomous indicators (abuse/dependence versus no) of nine lifetime SUDs (alcohol, cannabis, amphetamines, inhalants, hallucinogens, cocaine, opioids, phencyclidine, sedatives) in a sample of family studies of SUDs. They found that various binary variables of SUDs formed a unidimensional trait and that the trait score correlates with risky sexual behavior and treatment use. These findings suggest the feasibility of linking the latent factor score with other measures to better understand patients' severity profiles and inform nosological research (American Psychiatric Association [APA], 2010).

On the other hand, LCA can elucidate the presence of heterogeneity of poly-substance use or disorders by using the information from response patterns of various SUDs to classify individuals into a few mutually exclusive classes (Muthén and Muthén, 2000). For example, Wu et al. (2009c) found three LCA-defined groups of ecstasy users distinguished by level of drug use (primary marijuana, marijuana/cocaine, polysubstance); the most severe group was most likely to use addiction treatment. Agrawal et al. (2006) performed LCA on 10 binary indicators of lifetime drug use disorders and identified five groups (none, marijuana, stimulants/hallucinogens, prescription drugs, pervasive polysubstance) that differed in other psychiatric disorders. These results and others have shown that LCA-defined classes often vary from less-to-more-severe profiles in family history and multiple health indicators, suggesting LCA's utility in distinguishing less from more severe groups to inform research and differential intervention (e.g., Bucholz et al., 1996)

To date, studies often have focused on a single SUD and relied exclusively on either IRT or LCA. Here, we consider all available SUDs and compare IRT and LCA results to evaluate latent factor and class structures that may explain comorbid SUDs. While IRT analysis provides empirical information on item-level functioning along the latent liability, LCA may complement IRT results by differentiating less from more severe groups (heterogeneity). The utility of IRT-defined latent poly-SUD score and LCA-defined poly-SUD groups then is examined by regression procedures to assess their association with other standard assessments of clinical severity, including the Addiction Severity Index (ASI), HIV Risk Behavior Scale (HRBS), and SF-36 quality of life (Veilleux et al., 2010).

Due to high rates of comorbid SUDs in treatment-seeking patients and the need for empirical data to inform treatment research and classification of SUDs, we examined a geographically diverse sample of opioid-dependent adults to: (a) determine whether various SUDs relate to a latent poly-SUD trait or latent groups (poly-SUD versus severe poly-SUD); (b) identify demographic characteristics of opioid-dependent adults with increased odds of poly-SUD to inform subgroup disparities; and, as suggested by the DSM-5 workgroup (Saunders et al., 2007), (c) explore the utility of the latent poly-SUD by determining its associations with subscales from ASI, HRBS, and SF-36. We extend from prior research by examining study participants recruited from inpatient and outpatient addiction treatment settings at 12 programs across the U.S., focusing on current SUDs and other clinical 
measures to better reflect clinical indicators of severity, including nicotine use disorders, and using both continuous and categorical approaches to improve understanding of heterogeneity among individuals with SUDs.

\section{Methods}

\subsection{Data source}

Analyses were performed on the data from two multisite Clinical Trials Network (CTN) studies that evaluated the effectiveness of buprenorphine-naloxone and clonidine for opioid detoxification in inpatient $(\mathrm{N}=113)$ and outpatient $(\mathrm{N}=230)$ community-based treatment programs (Ling et al., 2005). Inpatients were recruited from six programs located in eastern, southeastern, midwestern, or western regions of the U.S.; outpatients were recruited from six programs located in eastern, midwestern, or western regions. Eligible patients included adults aged $\geq 18$ years who met DSM-IV criteria for opioid dependence and were in need of medical management for opioid withdrawal.

Patients were excluded if they had a serious psychiatric/medical condition that would make participation medically hazardous; had a known allergy or sensitivity to buprenorphine, naloxone, or clonidine; were receiving medications contraindicated with clonidine or had a systolic blood pressure $<100 \mathrm{~mm} \mathrm{Hg}$ or pulse $<56$ beats per minute; had been enrolled in a methadone treatment program or had participated in another investigational drug study within 30 days of study enrollment; or could not remain in the area for the duration of active treatment. To enhance the study's generalizability, dependence on other drugs did not exclude individuals from participation unless immediate medical attention was required to manage these disorders. Female participants were excluded if pregnant or lactating and were required to have a negative pregnancy test prior to randomization.

\subsection{Study variables}

Demographics included age, gender, race/ethnicity, education, and employment status. Pastyear SUDs (abuse or dependence: tobacco/nicotine, alcohol, cannabis, cocaine, inhalants, amphetamines/methamphetamine, sedatives, hallucinogens) were assessed by the DSM-IV checklist (Hudziak et al., 1993). Substance-specific dependence criteria were assessed, and endorsing $\geq 3$ of the seven DSM-IV dependence criteria resulted in a dependence diagnosis (tolerance, withdrawal, substance often taken in large amounts/for longer periods of time, persistent desire or unsuccessful attempt to cut down, a great deal of time spent in activities necessary to get the substance, important activities given up, continued substance use despite knowledge of having recurrent physical/psychological problems). Substance-specific abuse criteria were assessed, and endorsing $\geq 1$ of the four DSM-IV abuse criteria resulted in an abuse diagnosis (role interference, hazardous use, problems with the law, relationship problems).

Addiction severity at intake was assessed by the ASI—a standardized clinical interview widely used to assess substance use-related problems in alcohol use, drug use, medical, psychiatric, legal, family/social, and employment domains (McGahan et al., 1982; McLellan et al., 1985). Each ASI composite score (range 0-1) is mathematically derived to summarize responses to several questions within a problem area, with higher scores indicating greater problem severity.

HIV risk was assessed by the HRBS, an instrument with demonstrated reliability and construct validity in drug users (Darke et al., 1991; Petry, 2001). It assesses injection drug use (needle sharing, use of unclean needles) and unprotected sexual behaviors (multiple sexual partners, lack of condom use) in the past 30 days. Responses to each item were coded 
on a six-point scale (0-5), with higher values associated with more risky behaviors. Three summary scores were examined (total HIV risk, injection drug use risk, sexual risk).

Quality of life was assessed by the SF-36, a reliable and valid subject-administered instrument (Ware and Sherbourne, 1992). It measures health-related quality of life in physical functioning, role limitations due to physical health problems, role limitations due to emotional problems, energy/vitality, emotional well-being, social functioning, bodily pain, and general health perceptions. A higher score reflects better functioning.

\subsection{Data analyses}

Distributions of study variables were examined by descriptive analysis. Consistent with studies on poly-SUDs that have examined dichotomous abuse/dependence variables (Agrawal et al., 2006; Kirisci et al., 2006) and with findings showing that abuse and dependence tap one factor (Gillespie et al., 2007; Langenbucher et al., 2004), we examined six dichotomous variables (abuse/dependence versus no) for SUDs (nicotine, $41 \%$ of the sample; cocaine, 28\%; alcohol, 24\%; cannabis, 17\%; sedative, 6\%; amphetamine, 5\%) using discrete factor, IRT, and LCA procedures (Mplus V5.1; Muthén and Muthén, 2007). Hallucinogen $(1.5 \%)$ and inhalant $(0.3 \%)$ abuse/dependence were not included.

We conducted one-parameter and two-parameter IRT analyses because both have been shown to describe the unidimensionality of abuse/dependence symptoms in different studies, but little is known about their differences in SUD research (Gillespie et al., 2007; Kahler and Strong, 2006; Langenbucher et al., 2004). The one-parameter model assumes that item responses are a function of an individual's overall level of SUD problems and severity (threshold) of the items included. Item severity is defined by the location on a latent continuum at which an item has a 50\% likelihood of being present. An individual's total score is a summary of the responses to all items, making for simple summed score sufficiency. In addition to item severity, the two-parameter model also allows item discrimination to vary by SUD indicators, which measures the precision with which an indicator differentiates between individuals with levels of the latent trait above or below its severity level. In IRT, individuals with high levels of latent poly-SUD trait (scores) will have a higher likelihood of having SUDs.

Non-nested models of IRT and LCA were compared by considering the number of parameters, Bayesian information criterion (BIC), and sample-size adjusted BIC (ABIC) (Muthén, 2006). BIC/ABIC takes into account parsimony of the model, with lower values indicating a better model; they outperform Akaike information criterion in evaluating a fit to observed responses (Nylund et al. 2007). For LCA models, we used Vuong-Lo-MendellRubin likelihood ratio (VLMR) tests to determine model differences, and entropy (1=perfect delineation) to evaluate how well latent classes are distinguished (Lo et al., 2001). Both provide information about the quality of LCA-defined classes.

To evaluate associations between empirically defined latent variables and other clinical indicators, IRT-derived latent severity scores were regressed on demographics and clinical severity (scores of subscales from ASI, HRBS, and SF-36) via multiple indicators-multiple causes (MIMIC) modeling (Wu et al., 2010b; Wu et al., 2009a). MIMIC modeling incorporates the latent poly-SUD score from all six SUDs into a regression model and allows for statistical adjustment for variations in demographic covariates on the latent polySUD score while simultaneously estimating associations of the latent poly-SUD score with ASI, HRBS, and SF-36 variables. MIMIC modeling complements IRT analysis by providing a means by which to link the latent poly-SUD score with clinical severity measures. To elucidate clinical differences between LCA-defined classes, we conducted regression analyses to determine associations of LCA-defined class membership (based on posterior 
probabilities) with subscales from ASI, HRBS, and SF-36. Both complement one another as IRT describes the continuous distribution of poly-SUD, and LCA classifies groups based on the pattern of poly-SUDs.

\section{Results}

\subsection{Characteristics of opioid-dependent patients}

Of the 343 opioid-dependent patients, $67 \%$ were outpatients, $68 \%$ were men, $55 \%$ were nonwhites (31\%, African Americans; 20\%, Hispanics; 4\%, others), and 49\% were employed. Table 1 summarizes descriptive results of ASI, HRBS, and quality-of-life indicators.

\subsection{Factor, IRT, and LCA analysis of SUDs}

Factor analysis-An exploratory factor analysis of six dichotomous SUDs using weighted least-squares approach suggested one factor (comparative fit index $=1.0 ; 90 \%$ confidence interval of root mean square error of approximation $=0-0.06$; weighted root mean square residual=0.52) (Browne and Cudeck, 1993; Hu and Bentler, 1999). Factor loadings for nicotine, cocaine, alcohol, cannabis, amphetamine, and sedative abuse/dependence were $0.41,0.48,0.57,0.58,0.85$, and 0.61 , respectively (reliability coefficient $=0.76$ ).

Model comparisons-Fit indices from IRT, LCA, and factor models (using MLR or maximum likelihood parameter estimates) are summarized in Fig. 1. BIC (1842 vs. 1849) indicated that a one-parameter model fit better than a two-parameter IRT model, while ABIC (1823 vs. 1810) showed the opposite. Moreover, a two-class LCA model (with the lowest BIC and ABIC) fit the data better than IRT and other LCA models. Among LCA models, there were no differences in model fit between a two-class and a three-class model (VLMR test, $P=0.50$ ) and between a three-class and a four-class model (VLMR test, $P=0.60$ ). The two-class LCA model had a nearly perfect classification (entropy=0.99), indicating a high quality of classification. As suggested by the two-class LCA model, a twofactor model (nicotine/cocaine/alcohol/cannabis vs. amphetamines/sedatives; correlation of the two factors $=0.986$ ) was conducted for comparison. The two-factor model also had a larger BIC and ABIC than the two-class LCA model. Together, they indicated the two-class LCA model as more parsimonious than other models.

LCA-Fig. 2 shows that Class $1(90 \%)$ was distinct from Class $2(10 \%)$ in having lower rates of all SUDs: there were few between-class differences in nicotine abuse/dependence ( $41 \%$ vs. $49 \%)$; notable differences in alcohol ( $21 \%$ vs. $49 \%)$, cannabis ( $15 \%$ vs. $39 \%)$, and cocaine (25\% vs. $58 \%)$ abuse/dependence; striking differences in amphetamine (0\% vs. $55 \%)$ and sedative (0\% vs. $61 \%)$ abuse/dependence.

One-parameter IRT model-Given that the one-parameter model (Fig. 3a) provides an efficient means of summarizing all SUDs, translates them to an IRT score, and is more parsimonious than a two-parameter model (eFig. 1, on-line only), we present the oneparameter model results to complement LCA results. Of note, item characteristic curves (Fig. 3a) and item information curves (Fig. 3b) from a one-parameter model were consistent with a two-class LCA model by revealing that amphetamine and sedative abuse/dependence tapped similarly severe levels of the latent poly-SUD trait (almost overlapping item characteristic curves) than other disorders (cocaine/alcohol/cannabis, medium severity; nicotine, low severity). 


\subsection{Demographic predictors of the latent poly-SUD}

Compared with individuals in Class 1 (Table 2), individuals in Class 2 were more likely to be younger (mean age: 33 vs. 38 ), inpatients ( $52 \%$ vs. $31 \%$ ), and white ( $82 \%$ vs. $41 \%$ ). As a comparison, we report MIMIC modeling of the latent poly-SUD factor score from the six SUDs (one-parameter model), which showed that whites were more likely than African Americans and Hispanics to have an increased level of poly-SUD trait.

\subsection{Linking the latent poly-SUD with ASI, HRBS, and SF-36}

Categorical LCA-defined groups-Table 3 shows that individuals in Class 2 were more likely than individuals in Class 1 to have greater psychiatric problems and HIV risk scores. Controlling for gender, age, race/ethnicity, education, employment, and treatment setting, Class 2 still had a greater likelihood than Class 1 of having higher total HIV and sexual risk scores; the association between class membership and psychiatric problems was marginally significant $(P=0.064)$.

Continuous IRT-defined latent poly-SUD trait-Table 4 display associations between the latent poly-SUD score and subscales of ASI, HRBS, and SF-36 while controlling for treatment setting, gender, age, race/ethnicity, education, and employment status. Greater severity of ASI alcohol, drug use, and psychiatric problems and of total HIV risk were positively associated with increased levels of poly-SUD; three areas of quality of life were negatively associated with poly-SUD, indicating that a better functioning in physical health, bodily pain, and general health were associated with a decreased level of poly-SUD. As a check, we compared these results of MIMIC modeling of latent poly-SUD score based on the one-parameter model with results of MIMIC modeling of latent poly-SUD score based on a two-parameter model (data not shown). All significant associations from the former were found in the latter analysis; the latter also showed that physical functioning, energy, and emotional well-being were negatively associated with levels of poly-SUD.

\section{Discussion}

\subsection{Main findings}

Comorbid SUDs are a widespread problem among patients with opioid addiction, but little is known about how to use total diagnostic configurations to improve research on SUDs. One unique advantage of latent variable approaches is their use of fuller information from diverse patterns of all available SUDs and their translation into fewer meaningful groups (LCA) or a single interval IRT-based scale. Results suggest that a combined application of both categorical (LCA) and dimensional (IRT) approaches can improve understanding of comorbid SUDs and their associations with clinically important indicators. LCA elucidates heterogeneity of poly-SUD by distinguishing $10 \%$ of severe comorbid opioid-dependent individuals with high rates of all SUDs (especially amphetamine and sedative abuse/ dependence) from the 90\% with SUDs other than amphetamine and sedative abuse/ dependence. Although IRT conceptualizes SUD problems as a continuous trait, item-level results from one-parameter and two-parameter models also found that amphetamine and sedative abuse/dependence (almost overlapping item characteristic curves) tapped the severe-to-most-severe end of the latent poly-SUD trait. Therefore, assuming that the oneparameter IRT model's assumption is feasible, individuals who had amphetamine or sedative abuse/dependence also had higher rates of other SUDs examined than those without amphetamine and sedative abuse/dependence. This finding was clearly observed from LCA results (Fig. 2). 


\subsection{What this study adds}

Notably, these results suggest the complexity and limitations of conclusions drawn exclusively from either a categorical or a dimensional approach as the study constructs are constrained by each model. Specifically, LCA and IRT are important tools in research on SUDs due to needs for empirical data to inform revisions for DSM-5 and to incorporate dimensional measures to enhance the categorical DSM system (APA, 2010). However, reliance on either a categorical or dimensional approach exclusively may result in a narrow view of the findings. For example, the unidimensional IRT model does not generate categories of individuals, which are critical to clinical decision-making and ease of communication (APA, 2000). On the other hand, the categorical LCA approach could address this limitation by providing categories of individuals to help evaluate IRT results. As shown from findings, LCA pinpoints $10 \%$ of individuals with severe poly-SUDs who are clearly distinct from the other $90 \%$ in having higher rates of all SUDs, especially amphetamine (55\% vs. $0 \%)$ and sedative (61\% vs. $0 \%$ ) abuse/dependence. Two LCAdefined groups are almost perfectly classified (entropy=0.99). Markedly, item-level estimates from one- and two-parameter IRT models support this finding that individuals with amphetamine or sedative abuse/dependence had higher liabilities of exhibiting other SUDs than those without. Thus, combined use of LCA and IRT analyses may enhance research findings.

The finding that a LCA model fit to the SUD data empirically better than IRT models has implications for research and intervention. Similar studies have examined lifetime SUDs and used either LCA (Agrawal et al., 2006) or IRT methods (Kirisci et al., 2006). LCA research has shown that individuals with SUDs can be classified into a few subgroups distinct in the severity of SUDs and other psychiatric problems (Agrawal et al., 2006); IRT research has demonstrated that multiple SUDs form a unidimensional trait and that its score correlates with risky sexual behavior and treatment use (Kirisci et al., 2006). This study examined current SUDs and compared both approaches to comorbid SUDs. The two-class model indicates a high quality of classification. Importantly, LCA reveals that younger, white opioid-dependent individuals were disproportionally affected by SUDs (especially cocaine, amphetamines, sedatives), and this severe group had elevated levels of psychiatric problems and HIV risk, a finding that enhances understanding of elevated HIV risk and psychopathology among white opioid-dependent individuals and helps specify high-risk groups for focused interventions (Wu et al., 2010c). For instance, amphetamines/ methamphetamine appear to replace cocaine as the drug most associated with HIV risk behaviors in the U.S. (Rondinelli et al., 2009). Methamphetamine users also report more serious patterns of substance use and psychopathology than cocaine users (Copeland and Sorensen, 2001; Leamon et al., 2002). Similarly, among methadone maintenance patients, sedative/benzodiazepine use was associated with elevated rates of polysubstance use and psychopathology (Brands et al., 2008; Drake et al., 1993). Together, abuse of sedatives or amphetamines may serve to identify severe subsets of opioid-dependent individuals needing more intensive interventions.

Finally, this study extends IRT studies by examining both one- and two-parameter models and by demonstrating an innovative means of modeling SUDs simultaneously by transforming them into a single interval IRT-based scale linked with clinical indicators in MIMIC modeling. Both one- and two-parameter models showed that co-existing SUDs form a unifying unidimensional trait, ranging from less to more severe as various comorbid SUDs are present. This continuous construct is supported by MIMIC modeling in that severity of poly-SUD (factor score) was positively associated with greater alcohol/drug and psychiatric problems and with poorer health-related quality of life. These findings are consistent with others showing that drug abusers use multiple substances to enhance, moderate, or alleviate subjective psychoactive effects of drug use, and that repeated drug consumption further 
escalates users' risk for severe addiction and health problems (Koob, 2006; Leri et al., 2003).

\subsection{Limitations and strengths}

This study has limitations. The sample is not necessarily representative of all opioiddependent patients. The data rely on self-reports that are subject to recall or reporting bias. Nonetheless, studies have found that self-reported drug use, injecting behaviors, and risky sexual behaviors among problematic drug users are generally reliable (Darke, 1998; McElrath et al., 1994; Goldstein et al., 1995; Petry, 2001). This study also is limited by sample size $(\mathrm{N}=343)$. LCA requires a larger sample than IRT analysis to derive categories. The current sample size might contribute to the findings that regression analyses for LCAdefined groups found fewer significant associations than those for an IRT-defined continuous variable. Like prior research on comorbid SUDs, this study is constrained by use of diagnostic-level abuse/dependence indicators for the analysis (Agrawal et al., 2006; Kirisci et al., 2006). Ideally, all symptom-level items across all drugs should be analyzed simultaneously; however, no research paradigm addresses the complexity of modeling a very large number of items. Lastly, there are other more complex hybrid explanations of data (factor mixture model) that may be worthy of research.

\subsection{Conclusions}

Findings suggest that, regardless of whether SUDs were defined as a continuous trait or categories, individuals characterized by a high level of poly-SUD had elevated levels of psychiatric problems and HIV risk behaviors indicating differential intervention needs. The LCA approach provides practically useful information for informing more focused interventions by pinpointing specific groups with severe comorbid SUDs; the IRT conceptualization of SUDs as a continuous condition is heuristically consistent with the nature of a medical disorder, and as such, emphasizes screening and early prevention for managing a chronic addiction to avoid more costly consequences. Overall, these approaches appear to complement one another and support the recommendation to target multiple SUDs rather than a single SUD in addiction treatment and research (Rounsaville et al., 2003).

\section{Supplementary Material}

Refer to Web version on PubMed Central for supplementary material.

\section{Acknowledgments}

Role of Funding Sources: This work was made possible by grants from the U.S. National Institute on Drug Abuse of the National Institutes of Health (R21DA027503, R33DA027503, R01DA019623, and R01DA019901 to Li-Tzy Wu; R01DA026652 to William W. Eaton; U10 DA013045 to Walter Ling; HHSN271200522071C to Dan G. Blazer; K05DA017009 and U10DA013043 to George E. Woody). Its contents are solely the responsibility of the authors and do not necessarily represent the official views of the National Institutes of Health.

This work was approved by the Duke University Institutional Review Board. We thank Ms. Amanda McMillan for her editorial assistance.

\section{References}

Agrawal A, Lynskey MT, Madden PA, Bucholz KK, Heath AC. A latent class analysis of illicit drug abuse/dependence: results from the National Epidemiological Survey on Alcohol and Related Conditions. Addiction. 2007; 102:94-104. [PubMed: 17207127]

American Psychiatric Association. [Accessed October 15, 2010] Rationale for changes to substancerelated disorders - tentative new title of new combined section: addiction and related disorders. 2010. Available at http://www.dsm5.org/ProposedRevisions/Pages/proposedrevision.aspx?rid=431\# 
Brands B, Blake J, Marsh DC, Sproule B, Jeyapalan R, Li S. The impact of benzodiazepine use on methadone maintenance treatment outcomes. J Addict Dis. 2008; 27:37-48. [PubMed: 18956528]

Browne, MW.; Cudeck, R. Alternative ways of assessing model fit. In: Bollen, KA.; Long, JS., editors. Testing Structural Equation Models. Sage Publications; Newbury Park, CA: 1993. p. 136-162.

Bucholz KK, Heath AC, Reich T, Hesselbrock VM, Kramer JR, Nurnberger JI Jr, Schuckit MA. Can we subtype alcoholism? A latent class analysis of data from relatives of alcoholics in a multicenter family study of alcoholism. Alcohol Clin Exp Res. 1996; 20:1462-1471. [PubMed: 8947326]

Cattell RB. The scree test for the number of factors. Multivariate Behav Res. 1966; 1:245-276.

Carroll KM, Rounsaville BJ. On beyond urine: clinically useful assessment instruments in the treatment of drug dependence. Behav Res Ther. 2002; 40:1329-1344. [PubMed: 12384328]

Copeland AL, Sorensen JL. Differences between methamphetamine users and cocaine users in treatment. Drug Alcohol Depend. 2001; 62:91-95. [PubMed: 11173172]

Darke S, Hall W, Heather N, Ward J, Wodak A. The reliability and validity of a scale to measure HIV risk-taking behaviour among intravenous drug users. AIDS. 1991; 5:181-185. [PubMed: 2031690]

Darke S. Self-report among injecting drug users: a review. Drug Alcohol Depend. 1998; 51:253-263. discussion 267-268. [PubMed: 9787998]

Drake S, Swift W, Hall W, Ross M. Drug use, HIV risk-taking, and psychosocial correlates of benzodiazepine use among methadone maintenance clients. Drug Alcohol Depend. 1993; 34:6770. [PubMed: 7909749]

Gillespie NA, Neale MC, Prescott CA, Aggen SH, Kendler KS. Factor and item response analysis DSM-IV criteria for abuse of and dependence on cannabis, cocaine, hallucinogens, sedatives, stimulants and opioids. Addiction. 2007; 102:920-930. [PubMed: 17523987]

Goldstein MF, Friedman SR, Neaigus A, Jose B, Ildefonso G, Curtis R. Self-reports of HIV risk behavior by injecting drug users: are they reliable? Addiction. 1995; 90:1097-1104. [PubMed: 7549778]

$\mathrm{Hu}$ L, Bentler PM. Cutoff criteria for fit indexes in covariance structure analysis: conventional criteria versus new alternatives. Struct Equation Model. 1999; 6:1-55.

Hudziak J, Helzer JE, Wetzel MW, Kessel KB, McGee B, Janca A, Przybeck P. The use of the DSMIII-R checklist for initial diagnostic assessments. Compr Psychiatry. 1993; 34:375-383. [PubMed: 8131381]

Kahler CW, Strong DR. A Rasch model analysis of DSM-IV alcohol abuse and dependence items in the National Epidemiological Survey on Alcohol and Related Conditions. Alcohol Clin Exp Res. 2006; 30:1165-1175. [PubMed: 16792564]

Kendler KS, Jacobson KC, Prescott CA, Neale MC. Specificity of genetic and environmental risk factors for use and abuse/dependence of cannabis, cocaine, hallucinogens, sedatives, stimulants, and opiates in male twins. Am J Psychiatry. 2003; 160:687-695. [PubMed: 12668357]

Kirisci L, Vanyukov M, Dunn M, Tarter R. Item response theory modeling of substance use: an index based on 10 drug categories. Psychol Addict Behav. 2002; 16:290-298. [PubMed: 12503901]

Kirisci L, Tarter RE, Vanyukov M, Martin C, Mezzich A, Brown S. Application of item response theory to quantify substance use disorder severity. Addict Behav. 2006; 31:1035-1049. [PubMed: 16647219]

Koob GF. The neurobiology of addiction: a neuroadaptational view relevant for diagnosis. Addiction. 2006; 101(Suppl 1):23-30. [PubMed: 16930158]

Leamon MH, Gibson DR, Canning RD, Benjamin L. Hospitalization of patients with cocaine and amphetamine use disorders from a psychiatric emergency service. Psychiatr Serv. 2002; 53:14611466. [PubMed: 12407276]

Langenbucher JW, Labouvie E, Martin CS, Sanjuan PM, Bavly L, Kirisci L, Chung T. An application of item response theory analysis to alcohol, cannabis, and cocaine criteria in DSM-IV. J Abnorm Psychol. 2004; 113:72-80. [PubMed: 14992659]

Leri F, Bruneau J, Stewart J. Understanding polydrug use: review of heroin and cocaine co-use. Addiction. 2003; 98:7-22. [PubMed: 12492751]

Ling W, Amass L, Shoptaw S, Annon JJ, Hillhouse M, Babcock D, Brigham G, Harrer J, Reid M, Muir J, Buchan B, Orr D, Woody G, Krejci J, Ziedonis D. A multi-center randomized trial of buprenorphine-naloxone versus clonidine for opioid detoxification: findings from the National 
Institute on Drug Abuse Clinical Trials Network. Addiction. 2005; 100:1090-1100. [PubMed: 16042639]

Lo Y, Mendell NR, Rubin DB. Testing the number of components in a normal mixture. Biometrika. $2001 ; 88: 778$.

McElrath K, Chitwood DD, Griffin DK, Comerford M. The consistency of self-reported HIV risk behavior among injection drug users. Am J Public Health. 1994; 84:1965-1970. [PubMed: 7998638]

McGahan, PL.; Griffith, JA.; Parante, R.; McLellan, AT. Composite Scores from the Addiction Severity Index. National Institute on Drug Abuse Project DA02554 and the Veterans Administration; Washington, DC: 1982.

McLellan AT, Luborsky L, Cacciola J, Griffith J, Evans F, Barr HL, O’Brien CP. New data from the Addiction Severity Index: reliability and validity in three centers. J Nerv Ment Dis. 1985; 173:412-423. [PubMed: 4009158]

Muthén B. Should substance use disorders be considered as categorical or dimensional? Addiction. 2006; 101(Suppl 1):6-16.

Muthén B, Muthén LK. Integrating person-centered and variable-centered analyses: growth mixture modeling with latent trajectory classes. Alcohol Clin Exp Res. 2000; 24:882-889. [PubMed: 10888079]

Muthén, LK.; Muthén, BO. Mplus: Statistical Analysis with Latent Variables: User's Guide. Muthén and Muthén; Los Angeles: 2007.

Nylund KL, Asparouhov T, Muthén B. Deciding on the number of classes in latent class analysis and growth mixture modeling. A Monte Carlo simulation study. Struct Equ Model. 2007; 14:535-569.

Petry NM. Reliability of drug users' self-reported HIV risk behaviors using a brief, 11-item scale. Subst Use Misuse. 2001; 36:1731-1747. [PubMed: 11758820]

Rondinelli AJ, Ouellet LJ, Strathdee SA, Latka MH, Hudson SM, Hagan H, Garfein RS. Young adult injection drug users in the United States continue to practice HIV risk behaviors. Drug Alcohol Depend. 2009; 104:167-174. [PubMed: 19559543]

Rounsaville BJ, Petry NM, Carroll KM. Single versus multiple drug focus in substance abuse clinical trials research. Drug Alcohol Depend. 2003; 70:117-125. [PubMed: 12732403]

Saha TD, Chou SP, Grant BF. Toward an alcohol use disorder continuum using item response theory: results from the National Epidemiologic Survey on Alcohol and Related Conditions. Psychol Med. 2006; 36:931-941. [PubMed: 16563205]

Strain EC. Assessment and treatment of comorbid psychiatric disorders in opioid-dependent patients. Clin J Pain. 2002; 18:S14-S27. [PubMed: 12479251]

Saunders, JB.; Schuckit, MA.; Sirovatka, PJ.; Regier, DA. Diagnostic issues in substance use disorders: Refining the research agenda for DSM-IV. American Psychiatric Association; Arlington, VA: 2007.

Substance Abuse and Mental Health Services Administration. Treatment Episode Data Set (TEDS) Highlights-2007. National Admissions to Substance Abuse Treatment Services, Substance Abuse and Mental Health Services Administration, Office of Applied Studies; Rockville, MD: 2009.

Substance Abuse and Mental Health Services Administration. Results from the 2009 National Survey on Drug Use and Health: National Findings. Substance Abuse and Mental Health Services Administration, Office of Applied Studies; Rockville, MD: 2010.

Tsuang MT, Lyons MJ, Meyer JM, Doyle T, Eisen SA, Goldberg J, True W, Lin N, Toomey R, Eaves L. Co-occurrence of abuse of different drugs in men: the role of drug-specific and shared vulnerabilities. Arch Gen Psychiatry. 1998; 55:967-972. [PubMed: 9819064]

Vanyukov MM, Kirisci L, Moss L, Tarter RE, Reynolds MD, Maher BS, Kirillova GP, Ridenour T, Clark DB. Measurement of the risk for substance use disorders: phenotypic and genetic analysis of an index of common liability. Behav Genet. 2009; 39:233-244. [PubMed: 19377872]

Veilleux JC, Colvin PJ, Anderson J, York C, Heinz AJ. A review of opioid dependence treatment: pharmacological and psychosocial interventions to treat opioid addiction. Clin Psychol Rev. 2010; 30:155-166. [PubMed: 19926374]

Ware JE Jr, Sherbourne CD. The MOS 36-item short-form health survey (SF-36). I. Conceptual framework and item selection. Med Care. 1992; 30:473-483. [PubMed: 1593914] 
Wu LT, Pan JJ, Blazer DG, Tai B, Brooner RK, Stitzer ML, Patkar AA, Blaine JD. The construct and measurement equivalence of cocaine and opioid dependences: a National Drug Abuse Treatment Clinical Trials Network (CTN) study. Drug Alcohol Depend. 2009a; 103:114-123. [PubMed: 19423244]

Wu LT, Pan JJ, Blazer DG, Tai B, Stitzer ML, Brooner RK, Woody GE, Patkar AA, Blaine JD. An item response theory modeling of alcohol and marijuana dependences: a National Drug Abuse Treatment Clinical Trials Network study. J Stud Alcohol Drugs. 2009b; 70:414-425. [PubMed: 19371493]

Wu LT, Parrott AC, Ringwalt CL, Yang C, Blazer DG. The variety of ecstasy/MDMA users: results from the National Epidemiologic Survey on alcohol and related conditions. Am J Addict. 2009c; 18:452-461. [PubMed: 19874166]

Wu LT, Pan JJ, Yang C, Reeve BB, Blazer DG. An item response theory analysis of DSM-IV criteria for hallucinogen abuse and dependence in adolescents. Addict Behav. 2010a; 35:273-277. [PubMed: 19896773]

Wu LT, Pan JJ, Blazer DG, Tai B, Stitzer ML, Woody GE. Using a latent variable approach to inform gender and racial/ethnic differences in cocaine dependence: a National Drug Abuse Treatment Clinical Trials Network study. J Subst Abuse Treat. 2010b; 38:S70-S79. [PubMed: 20307798]

Wu LT, Ling W, Burchett B, Blazer DG, Shostak J, Woody GE. Gender and racial/ethnic differences in addiction severity, HIV risk, and quality of life among opioid-dependent patients: Results from the Clinical Trials Network. Subst Abuse Rehabil. 2010c; 1:13-22.

Wu LT, Woody GE, Yang C, Blazer DG. How do prescription opioid users differ from users of heroin or other drugs in psychopathology: results from the National Epidemiologic Survey on Alcohol and Related Conditions. J Addict Med. 2011; 5:28-35. [PubMed: 21532972] 


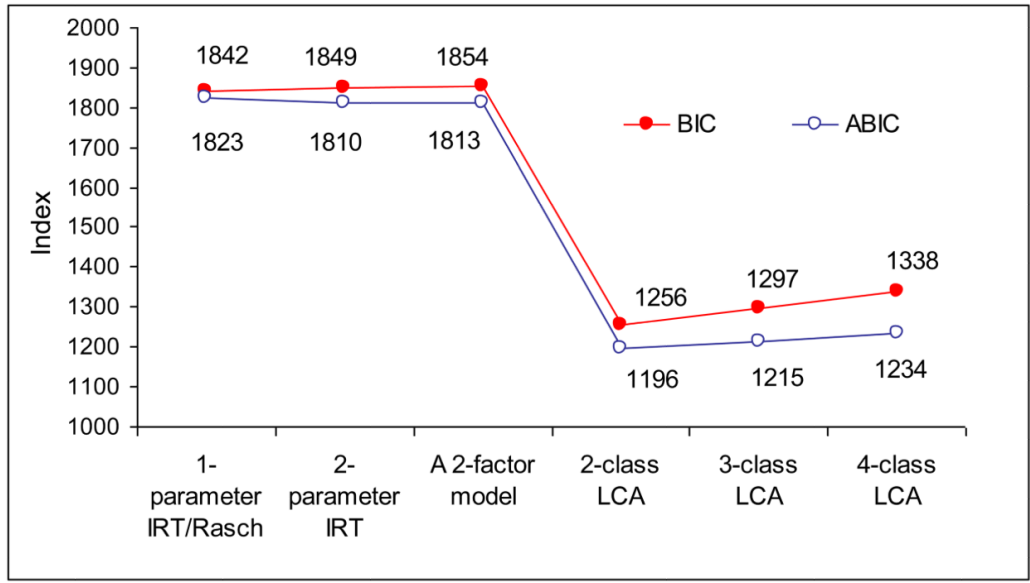

Fig. 1.

Comparisons of Bayesian information criterion (BIC) and sample-size adjusted BIC (ABIC) from item response theory (IRT), factor analysis, and latent class analysis (LCA) models for DSM-IV substance use disorders among adult patients in opiate detoxification treatment $(\mathrm{N}=343)$. 


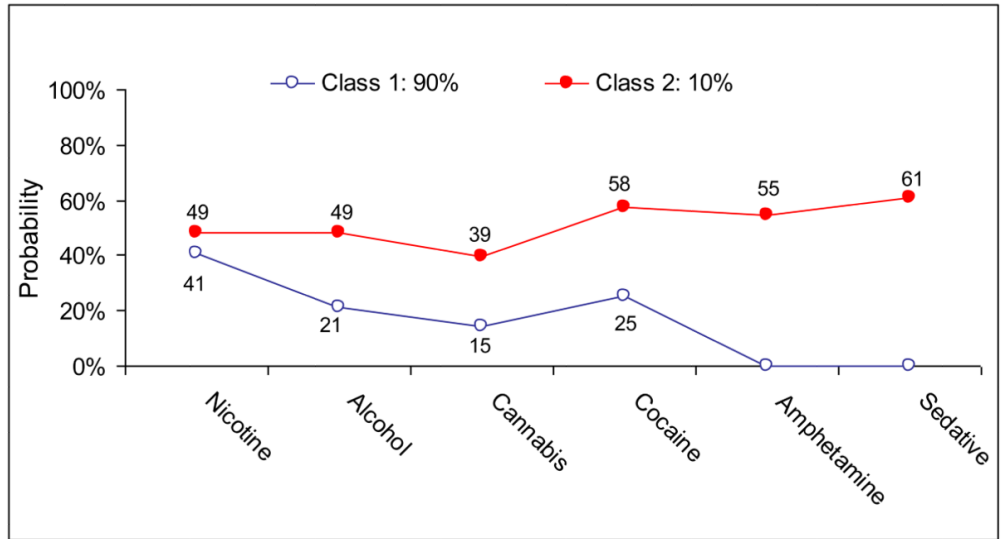

Fig. 2.

A latent class analysis of DSM-IV substance use disorders among adult patients in opiate detoxification treatment $(\mathrm{N}=343)$. 
Fig. 3a

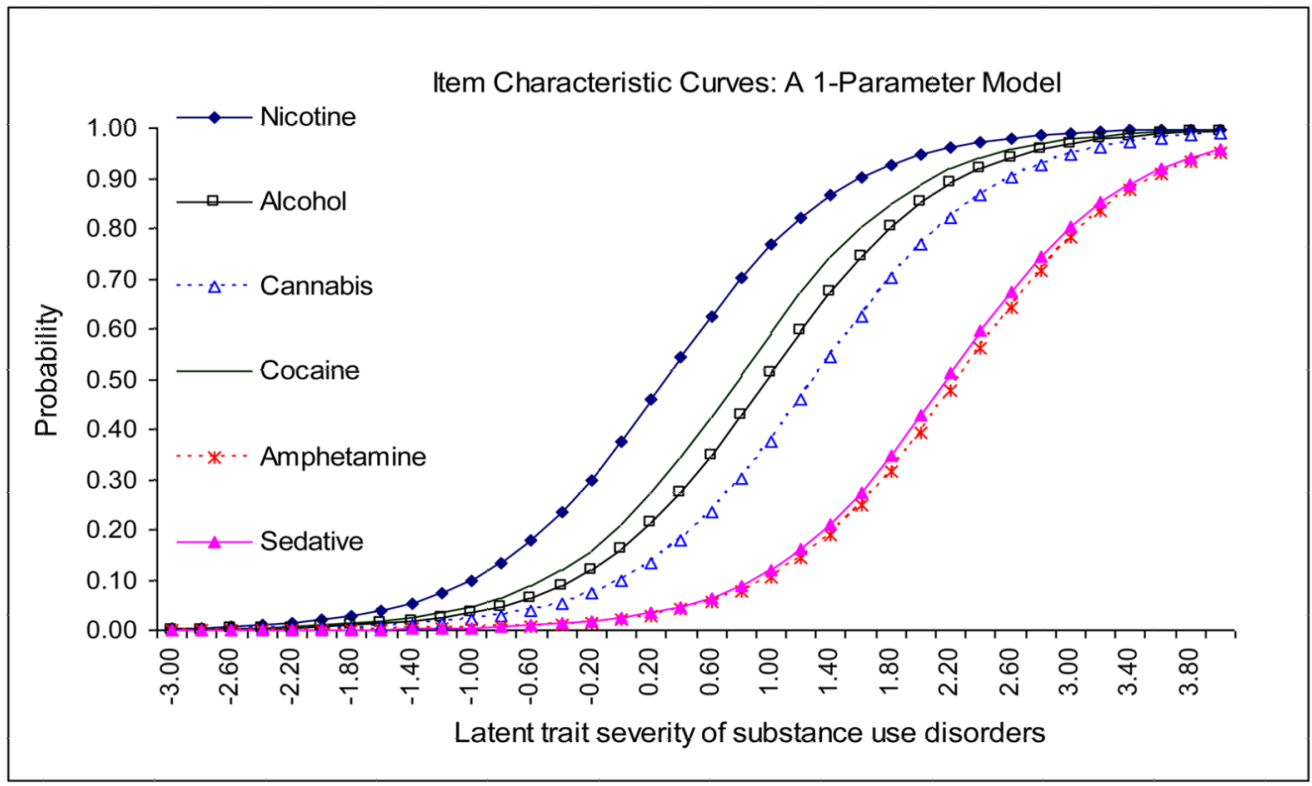

Fig. 3b

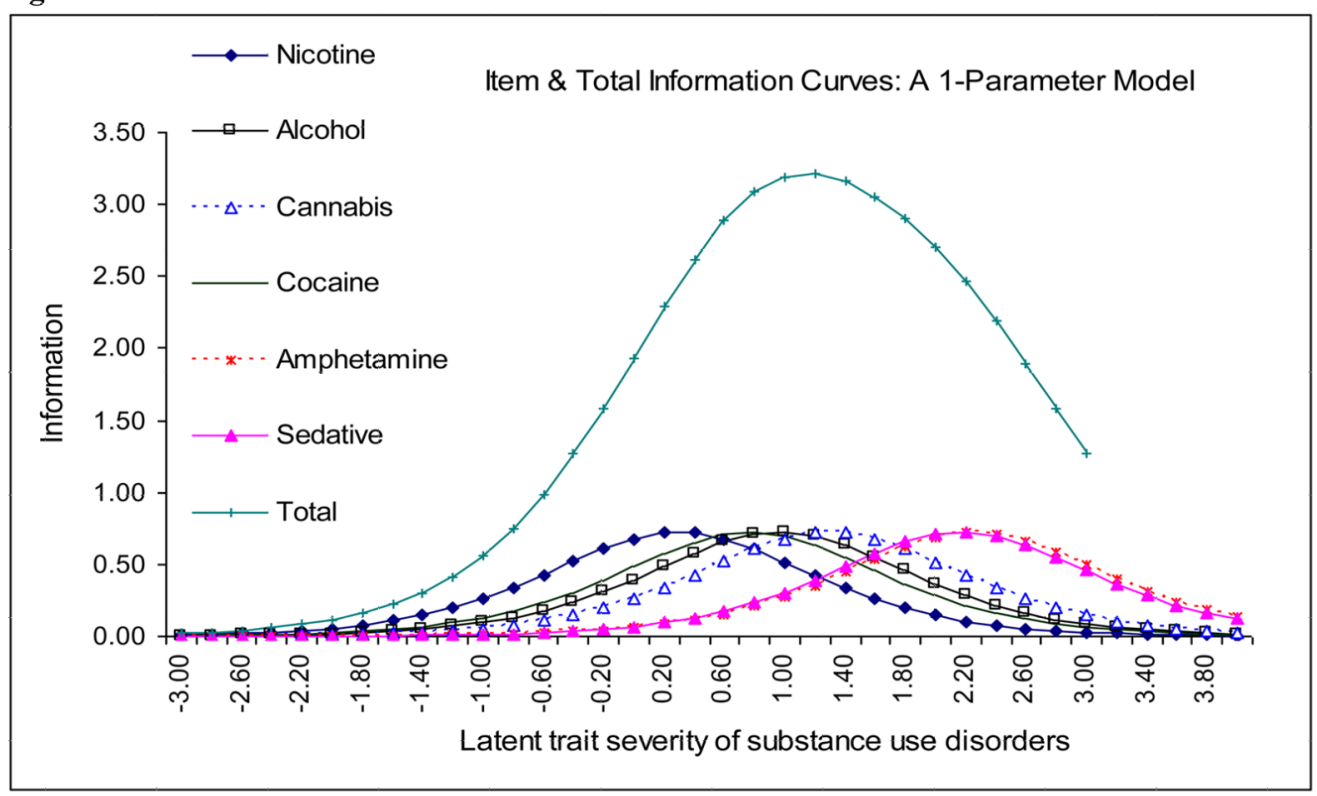

Figure 3.

Fig. 3a. The latent poly-substance use disorder syndrome among adult patients in opiate detoxification treatment $(\mathrm{N}=343)$ : a one-parameter item response theory model. Note: Severity parameters for each disorder: nicotine, 0.30; cocaine, 0.78; alcohol, 0.97; cannabis, 1.30; sedative, 2.17; amphetamine, 2.25.

Fig. 3b. The latent poly-substance use disorder syndrome among adult patients in opiate detoxification treatment $(\mathrm{N}=343)$ : item and total information curves in a one-parameter item response theory model. 
Table 1

Selected characteristics of adult patients in opiate addiction treatment $(\mathrm{N}=343)$

\begin{tabular}{|c|c|}
\hline \multicolumn{2}{|l|}{ Characteristics } \\
\hline \multicolumn{2}{|l|}{ Treatment setting, $\%$} \\
\hline Inpatient opiate detoxification & 32.94 \\
\hline Outpatient opiate detoxification & 67.06 \\
\hline \multicolumn{2}{|l|}{ Age in years } \\
\hline Mean (SD) & $37.50(10.17)$ \\
\hline \multicolumn{2}{|l|}{ Gender, $\%$} \\
\hline Male & 67.93 \\
\hline Female & 32.07 \\
\hline \multicolumn{2}{|l|}{ Race/ethnicity, \% } \\
\hline White & 45.19 \\
\hline African American & 30.90 \\
\hline Hispanic & 20.12 \\
\hline Other & 3.79 \\
\hline \multicolumn{2}{|l|}{ Education in years } \\
\hline Mean (SD) & $12.62(2.06)$ \\
\hline \multicolumn{2}{|l|}{ Past-month employment, $\%$} \\
\hline Employed/working & 49.27 \\
\hline Unemployed/not employed & 50.73 \\
\hline \multicolumn{2}{|l|}{ ASI subscales, mean (SE) } \\
\hline Alcohol problems & $0.07(0.01)$ \\
\hline Drug use problems & $0.33(0.01)$ \\
\hline Employment problems & $0.56(0.02)$ \\
\hline Family/social problems & $0.08(0.01)$ \\
\hline Legal problems & $0.15(0.01)$ \\
\hline Medical problems & $0.15(0.02)$ \\
\hline Psychiatric problems & $0.21(0.01)$ \\
\hline \multicolumn{2}{|l|}{ HRBS subscales, mean (SE) } \\
\hline Total HIV risk score & $12.21(0.49)$ \\
\hline Injecting drug use risk score & $6.91(0.35)$ \\
\hline Sexual risk score & $5.29(0.31)$ \\
\hline \multicolumn{2}{|l|}{ SF-36 subscale scores, mean (SE) } \\
\hline Physical functioning & $83.20(1.19)$ \\
\hline Role limitations due to physical health & $57.94(2.32)$ \\
\hline Role limitations due to emotional problems & $54.10(2.43)$ \\
\hline Energy/fatigue/vitality & $44.60(1.17)$ \\
\hline
\end{tabular}




\begin{tabular}{ll}
\hline Characteristics & \\
\hline Emotional well-being & $55.36(1.15)$ \\
Social functioning & $59.74(1.52)$ \\
Bodily pain & $63.81(1.50)$ \\
General health & $59.07(1.13)$ \\
\hline
\end{tabular}

SD: standard deviation; SE: standard error. 
Table 2

Demographic characteristics of the low versus high poly-substance use disorder groups among adult patients in opiate detoxification treatment $(\mathrm{N}=343)$

\begin{tabular}{|c|c|c|c|c|}
\hline Latent class membership & C1: Low severity & C2: High severity & $\chi^{2}(\mathrm{df})$ or t-test & Crude regression coefficient, $\beta$ \\
\hline Sample size & $\mathbf{N}=\mathbf{3 1 0}$ & $\mathrm{N}=33$ & & $\mathrm{~N}=\mathbf{3 4 3}$ \\
\hline \multicolumn{5}{|l|}{ Age in years } \\
\hline Mean (SE) & $37.99(0.57)$ & 32.97 (1.72) & $\mathrm{t}=2.77^{* *}$ & $-0.01 N S$ \\
\hline \multicolumn{5}{|l|}{ Education in years } \\
\hline Mean (SE) & $12.61(0.12)$ & $12.73(0.34)$ & $\mathrm{t}=0.32 \mathrm{NS}$ & $0.06 \mathrm{NS}$ \\
\hline \multicolumn{5}{|l|}{ Treatment setting, $\%$} \\
\hline Inpatient & 31.0 & 51.5 & $5.70(1)^{*}$ & $0.13 N S$ \\
\hline Outpatient & 69.0 & 48.5 & & 1.00 \\
\hline \multicolumn{5}{|l|}{ Gender, \% } \\
\hline Male & 68.1 & 66.7 & $0.03(1)$ & $0.01 N S$ \\
\hline Female & 31.9 & 33.3 & $N S$ & 1.00 \\
\hline \multicolumn{5}{|l|}{ Race/ethnicity,\% } \\
\hline White & 41.3 & 81.8 & $19.78(1)^{* *}$ & --- \\
\hline Non-white & 58.7 & 18.2 & & --- \\
\hline \multicolumn{5}{|l|}{ Race/ethnicity,\% } \\
\hline White & 41.3 & 81.8 & $22.67(3)^{* *}$ & 1.00 \\
\hline African American & 34.2 & 0 & & $-0.25^{*}$ \\
\hline Hispanic & 20.6 & 15.2 & & $-0.45^{* *}$ \\
\hline Other & 3.9 & 3.0 & & $-0.35 N S$ \\
\hline \multicolumn{5}{|l|}{ Employment, $\%$} \\
\hline Employed & 51.3 & 45.5 & $0.41(1)$ & $-0.07 N S$ \\
\hline Not employed & 48.7 & 54.5 & $N S$ & 1.00 \\
\hline
\end{tabular}

1 The MIMIC modeling of the latent factor score of the six substance use disorders and its association with background demographic variables.

NS: $P>0.05$;

${ }^{*} P<0.05$;

** $P<0.01$. 
Table 3

Regression analysis of ASI, HIV risk, and quality of life in relation to the poly-substance use disorder status among adult patients in opiate detoxification treatment $(\mathrm{N}=343)$

\begin{tabular}{|c|c|c|}
\hline Latent class membership & C2 vs. C1: Severe poly-SUD vs. poly-SUD & C2 vs. C1: Severe poly-SUD vs. poly-SUD \\
\hline Standardized regression coefficient $(\boldsymbol{\beta})$ & Crude $\beta$ & Adjusted $\beta^{2}$ \\
\hline \multicolumn{3}{|l|}{ ASI subscales } \\
\hline Alcohol problems & 0.05 & 0.10 \\
\hline Drug use problems & 0.09 & 0.07 \\
\hline Employment problems & -0.07 & 0.01 \\
\hline Family/social problems & 0.08 & 0.02 \\
\hline Legal problems & 0.05 & 0.04 \\
\hline Medical problems & 0.06 & 0.06 \\
\hline Psychiatric problems & $0.14^{* *}$ & $0.10^{\dagger}$ \\
\hline \multicolumn{3}{|l|}{ HRBS subscales } \\
\hline Total HIV risk score & $0.15^{* * *}$ & $0.10^{*}$ \\
\hline Injecting drug use risk score & $0.11^{*}$ & 0.05 \\
\hline Sexual risk score & $0.12^{*}$ & $0.14^{*}$ \\
\hline \multicolumn{3}{|l|}{ SF-36 subscales } \\
\hline Physical functioning & -0.08 & 0.07 \\
\hline Role limitations due to physical health & -0.09 & -0.01 \\
\hline Role limitations due to emotional problems & -0.02 & 0.003 \\
\hline Energy/fatigue/vitality & -0.05 & 0.003 \\
\hline Emotional well-being & -0.04 & -0.01 \\
\hline Social functioning & -0.02 & -0.01 \\
\hline Bodily pain & -0.03 & -0.01 \\
\hline General health & -0.03 & -0.02 \\
\hline \multicolumn{3}{|l|}{${ }^{+} \mathrm{P}<0.08$} \\
\hline \multicolumn{3}{|l|}{${ }^{*} P<0.05$} \\
\hline \multicolumn{3}{|l|}{${ }^{* *} P<0.01$} \\
\hline \multicolumn{3}{|l|}{$* * * * 0<0.001}$. \\
\hline
\end{tabular}


Table 4

The MIMIC modeling of the poly-substance use disorder syndrome and its association with ASI, HIV risk, and quality of life among adult patients in opiate detoxification treatment $(\mathrm{N}=343)$

\begin{tabular}{|c|c|c|}
\hline $\begin{array}{l}\text { The MIMIC model of the latent factor score of the six substance use disorders: } \\
\text { regression coefficient }(\beta)\end{array}$ & Standardized crude $\beta 1$ & Standardized adjusted $\beta^{2}$ \\
\hline \multicolumn{3}{|l|}{ ASI subscales } \\
\hline Alcohol problems & $0.40^{* * *}$ & $0.46^{* * *}$ \\
\hline Drug use problems & $0.51^{* * *}$ & $0.50^{* * *}$ \\
\hline Employment problems & -0.001 & -0.01 \\
\hline Family/social problems & $0.17^{*}$ & 0.15 \\
\hline Legal problems & 0.14 & 0.12 \\
\hline Medical problems & 0.12 & 0.11 \\
\hline Psychiatric problems & $0.26^{* * *}$ & $0.27^{* * *}$ \\
\hline \multicolumn{3}{|l|}{ HRBS subscales } \\
\hline Total HIV risk score & $0.18^{*}$ & $0.18^{*}$ \\
\hline Injecting drug use risk score & 0.13 & 0.11 \\
\hline Sexual risk score & 0.08 & 0.11 \\
\hline \multicolumn{3}{|l|}{ SF-36 subscales } \\
\hline Physical functioning & $-0.10^{*}$ & $-0.10^{\dagger}$ \\
\hline Role limitations due to physical health & $-0.22^{* *}$ & $-0.22^{* *}$ \\
\hline Role limitations due to emotional problems & -0.12 & -0.15 \\
\hline Energy/fatigue/vitality & -0.10 & -0.08 \\
\hline Emotional well-being & -0.12 & -0.09 \\
\hline Social functioning & -0.08 & -0.07 \\
\hline Bodily pain & $-0.22^{* * *}$ & $-0.21^{* *}$ \\
\hline General health & $-0.23^{* * *}$ & $-0.21^{* *}$ \\
\hline \multicolumn{3}{|l|}{$\mathrm{P}<0.08$} \\
\hline \multicolumn{3}{|l|}{$P<0.05$} \\
\hline \multicolumn{3}{|l|}{${ }^{* *} P<0.01$} \\
\hline \multicolumn{3}{|l|}{$* * * * 0<0.001$} \\
\hline$l$ The unadjusted model included one variable listed in that row. & & \\
\hline
\end{tabular}

